\title{
Encounters with Science at ULA, Venezuela: an incentive for learning
}

\author{
Patricia Rosenzweig $^{1} \dagger$, O. Escalona ${ }^{1}$, E. Guzmán ${ }^{1}$, \\ P. Bocaranda ${ }^{2}$, R. Echeverría ${ }^{3}$ and O. Naranjo ${ }^{1}$ \\ ${ }^{1}$ Grupo de Astrofísica Teórica, ${ }^{2}$ Centro de Semiconductores, ${ }^{3}$ Centro de Óptica, \\ Depto. de Física, Facultad de Ciencias, Núcleo La Hechicera, Universidad de Los Andes, \\ Mérida, Venezuela \\ email: patricia@ula.ve
}

\begin{abstract}
In the School of Science of the Universidad de Los Andes (ULA), in Mérida, Venezuela, a very successful event focused on elementary and high school students, was founded in 2000 . The name of this event is "Encounter with Physics, Chemistry, Mathematics, and Biology" (hereinafter "Encounters with Science"), and it integrates these disciplines, as well as Astronomy. Its main purpose is that young minds can become familiar with the methods of science inquiry and reasoning, and can understand the concepts and processes of the sciences through thoroughly prepared experiences.

"Encounters with Science" has grown each year in an exponential way. As a matter of fact, in its sixth edition (2005), the number of elementary and high school students coming from all over the country, has reached the outstanding number of approximately nine thousand. Among all the experiences that the students could be engaged in, were many involving Astronomy. These experiences were prepared by professors, together with graduate and undergraduate students, who are pursuing their degrees in all branches of science, including Astronomy. Although there is this incredible team of faculties and graduate and undergraduate students working together; the target is the students of the high and elementary schools. We certainly focus on the engaging and encouraging of students to experience scientific work at first hand.

This flourishing program is continuing to grow and to become strong. It has matured in the sense that now our professors have prepared an excellent didactic material that can, together with the hour/class teaching, prepare high school and elementary school students for a better understanding of science; particularly, helping in this way for a better education in Astronomy.

The main event of the Encounters lasts five days in the School of Science of ULA, but subsidiary events are spread all over the year and around the country through trips that our faculty members undertake with our students. Thereby, they reach places where students perhaps cannot attend the main event during its celebration. As a successful program, it can be interesting to see if other countries can adopt this method to recruit or to trigger the interest of students to pursue their studies in the Sciences.
\end{abstract}

Keywords. Spread of astronomy teaching, target elementary and high school education, impact in the country, astronomy in Venezuela

\section{Introduction}

The new changing time that is forth see in countries and universities, have converge in the need that our Alma Mater must be actively incorporated in the developing process that has affected the region and our country as a whole. In this sense, as faculty members, compromised to support, develop, and foment education, in the year 2000 we presented

$\dagger$ Present address: Universidad de Los Andes, Facultad de Ciencias, Núcleo La Hechicera, Mérida, Venezuela 
a proposal to the Physics Department of the School of Science of the Universidad de Los Andes (ULA), that very well fits with the changing process that is incubated in the educational environment. At that moment, its name was "Encounter with Physics" (Rosenzweig \& Escalona 2001, and Rosenzweig et al. 2001). It is important to point out that in this Department, most of the students pursuit their undergraduate and graduate theses, including astronomy and astrophysics topics. The idea of implementing this event was taken onto consideration not only by ULA, but by other private and public institutions devoted to the development of education and science in the region. In the overall, the main goal is to generate a proposal addressed to the quality of the process teaching/learning of basic Science, including the different fields, as astronomy as well.

A growing interest from the faculty members and our students, together with the interest of high and elementary school students, produced a successful attendance during the next consecutive years. As a matter of fact, the Encounters with Physics were celebrated until 2003, but something new was happening; that is, the participation of other faculty members from the Departments of Biology, Chemistry, and Mathematics. The enthusiasm was the same, the invited students could observe a growing amount of experiences making possible that we could trigger their interest to see not only how science is every where, but also the reason for which the phenomena can occur, and to allow the interaction with the speaker and to give their own opinion. This way, we could transform the high and elementary school student from a guest to a performer. On the other hand, our faculty members, as well as our students, had to improve the way to explain the phenomena, the laws that are involved in order of not misleading the young minds of our invited. Due to the inclusion of the other basic sciences, starting the year 2004, in its fifth edition (Rosenzweig 2004), the Encounter with Physics, started to be called Encounter with Physics, Chemistry, Mathematics, and Biology (hereinafter "Encounters with Science"), with experiences involving astronomy as well.

In section 2 we will explain the motivation, section 3 will show the strategy required for the creation and sequence of the event, section 4 will show some impressive statistics, section 5 a chain reaction from the schools, other universities and regions, as a consequence of the encounters, and section 6 , the future.

\section{Motivation}

The very first motivation to pursuit an event of this magnitude is related with a common problem that is facing the science in the whole world. That is, the deterioration of its teaching and the so pronounced lack of interest from the students point of view, and the lack of conscience about its importance in our lives, as well. It is a world wide need, especially in Venezuela, to promote not only the innovation, but the development of technology in all areas (Rosenzweig \& Escalona 2001, and Rosenzweig et al. 2001); thereby, the so badly called hard sciences cannot be immune to this need. For this mainly reason, we dont want to spear any effort in order to support all type of events that can contribute to the spreading and better performance in the teaching of these disciplines.

It is sad, but certainly truth, that sometimes the lack of motivation starts from the teacher itself, perhaps due to the fat that he/she cannot find a support from the universities or from the educational system. Thereby, we are eager to promote the encouragement not only to the high and elementary school students, but also to their teachers in order to have a better performance in the process of teaching/learning of science. The motivation to organize these events goes beyond of just having an exposition of experiences. As time goes by, we want to converge in the elaboration of specific projects that involve 
the conclusion of a modern didactic focused in the good learning of this important field of knowledge.

In order to seal our motivation, important facts have been present since the beginning, that is we have committed ourselves so these events can survive time, and to have a systematic close look on schools and high schools through guidance, to give advises, corrections, and proposed researches in their educational projects. Our Professors and undergraduate students, as well as graduate students, have elaborate books (Memorias del I Encuentro con la Física 2001 and Memorias del IV Encuentro con la Física 2004), so that we can distribute to the schools as a guide for them to elaborate theirs own experiments. These memoirs include many experiments in the biology, mathematics, chemistry, physics and astronomy.

\section{Strategy involved for the creation and sequence of the events}

In what follows, a brief explanation of the main steps that should be taken into account, in order to crystallize the motivation, of a better learning/teaching of science.

(a) To encourage and to motivate the faculty members that do believe in the lack of interest and deterioration for the learning of science. A better preparation of the students before their entry in the University, will easier their work and give them the certainty of a successful teaching at this level.

(b) To encourage the university students as well, in order to be a good helping hand for the faculty members. Making them to understand that they will create a "dynamical duo" with one target: the primary and high school students.

(c) To contact the educational District responsible of the schools, and make them understand the benefits of a well prepared student population.

(d) To have a well prepared personnel, as a link between the university and all the schools. By well prepared it is understood that this personnel knows the member of the school districts and the statistics in each school. By the former, we can assure the green light for schools to participate. By the latter, we can know how many students of each school can be invited from the relative point of view (a necessary limited amount of students is imposed but, the ones that will attend can serve as multipliers for the others).

(e) To have an appealing material to promote the event. Every body, especially youngsters are easier to enrol when they see a nice and well prepared material.

(f) To search for financial support from inner and outer organizations. The former being the university, and the latter, both private and public organisms must be involved. Usually, the events require a registration fee, but in many cases schools dont have high budgets. For this, the Encounters dont have any fee for registration.

(g) To do an effort in order to give to the invited students a certificate of attendance. Some students might discard it but others can keep them as a reminder of an important event and, why not, the decision to be enrolled in this branch of knowledge as is the basic sciences.

(h) To make an extra effort in order to give to the invited students a demonstration of care by giving them some refreshments. Some times, bakery shops are among the institutions eager to help. It is important to notice that many students come from very far away and they must make a very early trip with no chance to have a decent meal.

(i) To have in mind, above all, that we must show to the invited students that the School of Science is not a hard place and that there are living professors and students, eager to open their helping arms in order to make understand that science is just a way to understand nature. 

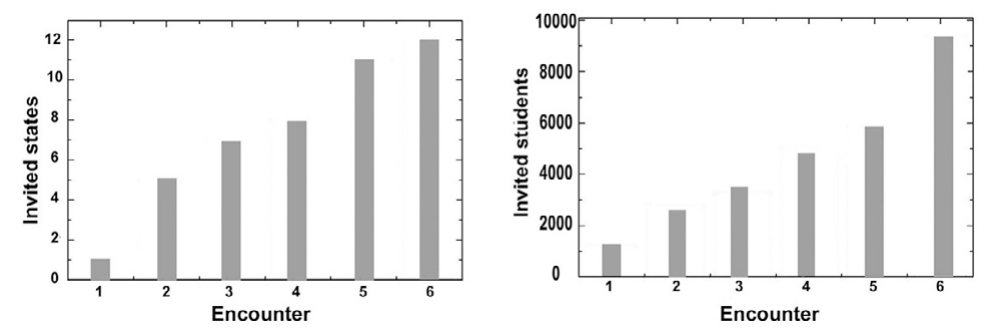

Figure 1. Statistic that show how the event has been growing as part of the national interest for this initiative

\section{Statistics}

In the year 2000, we were dreamers thinking that science could fulfil the interest of young people, perhaps with potential to do so but not knowing so. It seemed an impossible mission to trigger their intellectual creativity and to vanish their fear for something that was really unknown for them. Nevertheless, in its sixth edition, the School of Science of ULA has proven that this task called Encounters with Science, a complete pedagogic program, is worthwhile and that it was a certainty to have this dream. The seed has spread and is continuing to grow and to give fruits all over the country. Now a day, we are positively convinced that the plantation of science must be pursuit since the early stages of the educational stair, and we are now obliged to continue to organize this event as long as it takes. We are optimist in this assignment since, year after year, there are more professors and students enthusiastic to design and implement demonstrative and didactic experiences, several of them truly original, and all of them having a common factor: to show in a very illustrative, and simple way, the beauty of the phenomena that involve science. The integration of all the disciplines has shown that indeed it has triumphed.

Not only the integration of all the disciplines and the enthusiasm of the professors, and students, have shown that the Encounters are here to stay, but the incredible interest of so many schools and high schools to attend. Our guests, the high and elementary students, want to come every year. In the year 2000, only 1200 students from the State of Mérida came to the School of Science of ULA; last year, in its sixth edition, approximately 9000 students from 12 states of Venezuela came. The statistics are shown in the histograms that follow (figure 1). Also, in figure 2, the map of Venezuela shows how the event has expanded all over the country. We must point out that, because of financial problems, the students find it hard to come every year. We are trying to elaborate agreements, in order for other institutions to join this work.

\section{A chain reaction}

Besides the unquestionable success of this event during five days on the grounds of the School of science, not only the students from our careers are the actors but also elementary, high schools and even very young children are selected to present their work in front of the contemporaneous invited. The selection of the young guests is performed because now, the elementary and high school students do their own Encounters with Sciences because we have triggered this interest. In their event, we go and select the best experiments due to their creativity and, of course, we take into account the preparation of the students. It is truly a beautiful spectacle to see all the schools in a Science festivity, friends cheering up the others as a demonstration of support and, above all, the pride to 


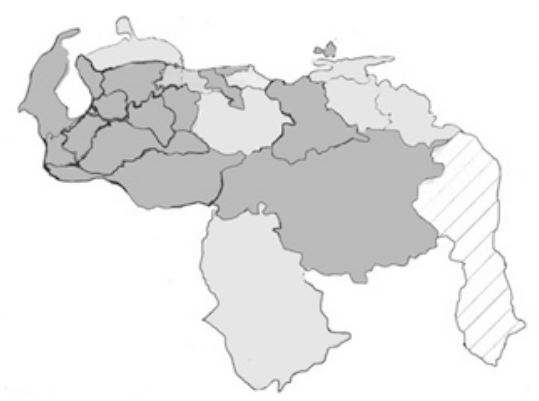

Figure 2. Map of Venezuela where shaded states indicate the ones that participated in the event and from where our professors and students came

go to the renowned School of Science of ULA, and be able to be in an equal position of the students of the wrongly called the hard sciences.

As far as we know, already five schools are doing their own events for approximately four years, and the interest is growing every day. We have the knowledge that in other states, farther than the surroundings of Mérida, there are more schools devoted to extend the main event taking place at ULA. With these schools, we are articulating the Web of Encounters in order to create a big research platform composed by students and teachers of public and private schools and the School of Science; thereby, to conduct a hand by hand work with the final aim to give to our professional help in the teaching of the sciences, that will allow to have criteria that will be incident in its better learning processes.

But this "festivity" does not even end at this point; as a matter of fact we have been spreading out workshops for the capitation and actualization of teachers, in several states of Venezuela, bringing interesting oral presentations and, in a smaller scale, some experiments that we present in the main event. This task is performed with an alliance with other universities and institutions. Per example, we have been presenting this work in the state of Nueva Esparta (Porlamar) with the Universidad de Oriente; in Barinas with the Universidad de Los Llanos Ezequiel Zamora; in Trujillo with the extension of ULA in this state; in Zulia (Maracaibo and Santa Bárbara) with La Universidad del Zulia and Universidad del Sur del Lago, respectively; in Caracas with the Museum of Science; in Táchira with local schools and School Districts; and, in Falcón (Dabajuro) with the Universidad Francisco de Miranda. In this last place, a curious and gratification issue arose when very humble people from this small village, requested that we present the event in a church! In figure 2 we show the places were the events have taken place.

Also, we have prepared a didactic material (books, manuals, promotional kits, didactic toys, etc.) that resumes all the scientific experiments that we show in the several activities that we have mentioned, and we give it to all the schools with no cost.

Well, no wonder our Quijote de La Mancha dream called Encounters with Science has earned, in 2004, the first edition of the Prize for the Scientific Spreading, Mention: Best Initiative. All the state of Mérida, and specially ULA, was very happy and proud for this honor because it is a truly event of and for the people and for the next generation of scientist (hopefully). As a matter of fact, in its second edition a special mention was given to some students of the School of Science of ULA for being implementing, with dedication and professionalism, the experiments during the Encounters with Science. 


\section{The future}

It is obvious that the Encounters with Science have now a national status and a clear success due to several reasons: (a) the ever growing interest of our faculty members and our students, (b) the interest from primary and high school students, and (c) the financial help from several organisms in ULA (School of Science, several organisms under the tutoring of ULA's President, Academic and Administrative Vice-Presidents), FundaciteMérida, FONACIT, OPSU, Laboratorios Valmorca, Fundación Polar, other private and official organisms, and individuals in general. For the latter, it seems a long list and, perhaps, we can think that we get a lot of aid; the reality is not so, every year we have a lack in the financial sense that makes us think that we will not be able to cope with the main event and all the other activities already described. But, we do a large effort to not let down such an important mission for education. We do this effort with the clear conviction that doing the incredible task of designing, creating, explaining in a simple way some experiments that trigger the imagination of young minds; we will leave a legacy that will last in time. A future would be certain in obtaining funds from even international organizations and to be able to insert this event in the official organisms that have the heavy duty to make Science as one of the attractive options for a career.

We hope that this opportunity that we have been given to spread the news over this event in and internationally way, can help us to find sensible people that can adopt part of the financial problem that we face.

\section{Acknowledgements}

$\mathrm{PR}$ is thankful for the invitation of the IAU GA Special Session 5, specially to J.B. Hearnshaw; and, for the financial support of the IAU GA; CDCHT-ULA (under project SE-C-02-06-05); H. Ruiz and M. Bonucci, Academic and Administrative Vice-Presidents of ULA, respectively, and J. Andérez Director of the Inter-institutional Relations of ULA.

\section{References}

Memorias del I Encuentro con la Física 2001, in: P. Rosenzweig, O. Escalona, A. Noguera, V. Sagredo, and A. Paniagua (eds.), Facultad de Ciencias, ULA, pp. 184

Memorias del IV Encuentro con la Física 2004, in: V. García (ed.), , Facultad de Ciencias, ULA, pp. 115

Rosenzweig, P. 2004, in: N. Pulido (ed.), Investigación Revista del Consejo de Desarrollo Científico, Humanístico y Tecnológico, $\mathrm{V}$ edicin de un acto pedagógico de pertinencia social. Sembrando Ciencia (CDCHT - ULA), No. 10, p. 56

Rosenzweig, P. \& Escalona, O. 2001, in: N.Pulido (ed.), Investigación Revista del Consejo de Desarrollo Científico, Humanístico y Tecnológico, Encuentros con la Física (CDCHT ULA), No. 5, p. 34

Rosenzweig, P., Escalona, O., Noguera, A., Sagredo, V. \& Paniagua, A. 2001, I Congreso Regional para la Enseñanza de la Física, Primer Encuentro con la Física (UNET), p. 51 